\title{
THE TREATMENT OF PREGNANCY AND LABOR COMPLICATED BY CARDIAC DISEASE*
}

\author{
By Franklin S. Newrelt, M.D., F.A.C.S., Boston, Mass.
}

Q 0 far as can be determined from statistics, approximately 2 per cent of $D$ all obstetric cases are complicated by definite valvular disease of the heart, more or less serious in degree, which renders the prognosis somewhat doubtful, either in the immediate pregnancy or in the years to come. When the patients who are suffering from myocardial change, whether acute, following some recent infectious process, or chronic, are included, it seems fair to assume that about 3 per cent of all parturient women have a cardiac condition which may be expceted to rcact more or less seriously to the strain which pregnancy and labor impose on the heart. There is probably no obstetric complication. which calls for greater judgment on the part of the attendant than do cardiac lesions, since not only the immediate prognosis for mother and child, but the future health of the mother depends on the proper conduct of pregnancy and labor.

The obstetrician is not infrequently called on to decide whether the risks of pregnancy and labor are too great to be undertaken by a patient who is known to have a heart lesion or whether pregnaney may be undertaken with a reasonable chance for an immediately successful outcome for both mother and child, and without serious danger that the mother may be left a cardiac invalid at an early date. More commonly, however, he is consulted when the pregnancy is already an established fact and the question to be answered then is whether the pregnancy must be terminated at an early date for the sake of saving the life or health of the mother or be allowed to continue, in the absence of scrious symptoms, to, or nearly to, full tcrm. If he decides, after due consideration, that it is unwise to allow the pregnancy to go on, the method to be adopted for the termination of pregnancy has an important bearing on the future life and health of the patient. In the cases where the continuation of pregnancy seems justifiable, the care given the patient during pregnancy and the method of delivery at term have an important bearing not only on the immediate life of the patient, but also on her future. The decision of the obstetrician in the individual case is evidently, therefore, not a simple matter, since an crror of judgment may involve the loss of the maternal life or health, or result in forbidding childbearing needlessly to a woman who would gladly run some risks for the sake of having a child, if there is any method of treatment by which the risks can be so minimized as to be justifiable.

The cardiac patient who attempts pregnancy must be considered as a relatively unfavorable risk, even under the best conditions. Cardiac damage is incvitable, sinec the cardiac reserve will be depleted to some extent by the additional strain imposed on the heart, and the pregnancy must be so con-

*Read by title at the Forty-fiftl Anumal Meeting of the American Gynecological Saciety, Chicago, May $24-26,1920$. 
ducted as to give the best chance for a favorable result for both patients, while delivery must be so accomplished as to impose the least possible strain on the damaged heart. It is not enough for the obstetrician to take into account a successiul result in the immediate pregnancy, but he must bear in mind the fact that the strain of pregnancy is a serious one and that his patient's future health depends largely on the care which she receives. He must, therefore, take into consideration the effect which the strain of pregnancy and labor will have on the damaged heart in the years to come as well as at the present time, and so conduct the case that the cardiac reserve shall be depleted to the least possible extent.

Before considering the methods to be adopted in the care of the individual case certain facts must be accepted as true if the patient is to be given the best chance for a favorable result. First, no matter what the nature of the cardiac lesion in the given case, the increased strain which pregnancy and labor unavoidably impose on the damaged heart must diminish to a certain extent the cardiac reserve and thus to a greater or less degree shorten the patient's life. The damage may be such as to result in death or chronic invalidism unless the pregnancy is terminated early and the child sacrificed, or it may be slight in degree and only become evident as the patient grows older. But in my opinion every paticnt with a cardiac lesion who attempts childbearing must pay some price in length of days for each child, the exact amount being dependent on the nature of the cardiac lesion, the condition of the heart muscle at the beginning of pregnancy and the success with which the heart is protected from all unnecessary strain during pregnancy and at the time of labor.

Second, it is impossible to estimate accurately the extent of the damage which will result to the heart from the strain of pregnancy, even under the best conditions, in spitc of the most careful consideration of all the factors present in the individual case. My experience has shown that in two patients with an apparently equal degree of cardiac damage, which seems to be perfectly compensated under normal conditions, one will develop more or less serious symptoms during pregnancy and labor, while the other will pass through the strain without developing any unfavorable symptoms. I believe that there are no accurate means of determining the effect of the pregnaney on the heart and it is exceedingly difficult to formulate an accurate prognosis for the given case. I can recall several instances in which the results, both good and bad, have proved so widely at variance with the opinions expressed by competent internists aftcr careful study of the patient that I am convinced that the only fair prognosis which can be given to a cardiac patient is that more or less damage to the heart will result from the attempt to have children, and that her life will be shortened to some extent, but that the actual degree of damage in the individual case cannot be estimated in advance. There arc, of coursc, certain patients in whom the cardiac history, taken in conjunction with the physical findings, is such that it is evident that childbearing will either prove fatal or leave the patient a chronic invalid, and in these cases pregnancy should either be forbidden, if the obstetrician 
is consulted in advance, or should be interfered with promptly as soon as the facts are clearly appreciated. In the majority of cases, however, a patient-if otherwise in good health, without a history of previous decompensation and whose heart muscle is presumably sound-can be advised that in all probability pregnancy can be undertaken, under proper supervision, with an excellent chance of an immediately successful result, but that the strain on the heart will cause some damage which will ultimately shorten her life, though to what extent it is impossible to predict accurately. Thercfore, it is a question for the patient to decide herself, whether she is willing to pay an indefinite price for the sake of having children, the exact amount being largely determined by the care with which pregnancy and labor are conducted. There is always, however, an element of uncertainty, and relatively favorable cases, even under competent supervision, sometimes go badly.

It has been a long established tradition of the medical profession that if a patient with a cardiac lesion consults her physician as to the advisability of pregnancy, she should be strongly cautioned against it. If the only problem to be determined in the given case were the prolongation of the patient's life to the utmost extent this advice would be sound, since there can be no question but that the avoidance of all possible strain on the heart will do more to conserve its reserve than any other method of treatment. There are, however, many women with eardiae lesions who feel that life is incomplete unless they have ehildren, and who, while not willing to sacrifice their life or immediate health to gratify this desire, are perfectly willing to shorten their lives to a greater or less extent. In advising these cases as to the justifiability of attempting pregnancy, the judgment of the obstetrician is often taxed to the utmost. The nature of the lesion, the history of the patient as regards symptoms of previous decompensation, the probable condition of the heart muscle, and the care which the patient is able and willing to receive, both during pregnancy and at the time of labor, must all receive due consideration before proper advice can be given to the individual patient.

Experience has shown that certain lesions are more seriously affected by pregnancy than others. Of these, mitral stenosis, either alone or in combination with other lesions, is distinctly the most serious. The aortic lesions come next in order, and mitral regurgitation, while not entirely negligible, is of relatively minor importance. If myocarditis can be demonstrated, the seriousness of the prognosis is definitely increased. If a patient has never had any signs of decompensation either in her ordinary life or in previous pregnancies and has suffered no limitation of her ordinary activities on account of the cardiac lesion, the outlook for a successful pregnaney with a minimum of damage is good. If, however, there have been previous attacks of decompensation, or if the patient develops symptoms referable to the heart on what would be ordinary exertion for the healthy woman, the prognosis is to say the least doubtful, and pregnancy should be advised against, irrespective of the nature of the lesion. If a patient's cireumstances are such, other conditions being satisfactory, that she can take proper care of herself during pregnancy in order to minimize the damage to the heart and can command such 
obstetrical skill at the time of labor as to save the heart from unduo strain, pregnancy is often justifiable, whereas if the opposite were the case, pregnancy should be absolutely forbidden. Furthermore each patient must be informed that if cardiac symptoms unexpectedly arise during pregnancy in spite of careful supervision, a prompt termination of the pregnancy will probably be necessary, even in apparently favorable cases, and that under such circumstances a sufficient degree of cardiac damage may result to render her a cardiac invalid to a greater or less extent, even though the pregnancy be ended in the early months. Under these conditions it is fair to advise a cardiac patient that it is justifiable for her to attempt childbearing, but otherwise it should be absolutely forbidden.

In most cases, however, pregnancy is already a fact when the patient consults her physician for care, and the problems which he has to decide are first whether a continuance of the pregnancy is justifiable, and if not, by what means is it best tcrminated; second, if continuance of the pregnancy seems wise, what routine shall the patient adopt to minimize the strain of pregnancy on the heart; and third, how shall she best be delivered if pregnancy is successfully accomplished.

The question as to whether the pregnancy shonld be allowed to continue or must be terminated promptly depends on several factors. Some authorities go so far as to say that the discovery of a mitral stenosis is suffieient indication for immediate abortion, while others feel that heart disease is not a contraindication for pregnandy and lahor. Neither position is correet as is evidenced by the fact that many patients with a marked mitral stenosis or an aortic lesion go through pregnancy with litlle apparent damage and regain their ordinary health after delivery, while on the other hand in a certain proportion of cases cardiac decompensation develops, which sometimes results in death or invalidism even though a patient is given the best possible care. It is evident, therefore, that the problem is one which must be settled for each individual patient, and no rule can be laid down.

If a patient, with mitral stenosis or aortic disease has never had symptoms referable to the heart (at least of a severe character), and the heart is performing its work properly when the paticnt applies for adviee, such a patient should be placed on a definite routine, the purpose of which is to remove all possible strain from the heart, and the pregnancy should be allowed to go on under close observation, interference being only advisable in case symptoms develop. This is particularly true in patients who have had the cardiac lesion for a considerable period of time and have suffered no disability from it. If, however, the patient when under proper supervision has suffered attacks of decompensation, if when she applies for care the heart is already causing symptoms, or if her normal activities have in the past been seriously hampered on account of the heart, a patient should be advised that it is unwise to allow the pregnancy to go on, since a serious failure of compensation may develop at any time with possibly fatal results.

If abortion seems advisable the method of operation is of considerable importance. It seems to me that a termination of the pregnancy is only a partial 
operation in these cases since it leaves the patient in a condition to again become pregnant with the necessity of future abortions, and, therefore, I believe that unless the patient's condition is such as to contraindicate an abdominal operation the abortion is best accomplished by abdominal hysterotomy. Sterilization should be performed at the same time to obviate the danger of future abortions, since the necessity of lerminating one pregnancy for cardiac reasons should be considered as an absolute contraindication to future pregnancies.

I believe it is little, if any, more dangerous for a patient with a bar heart to be delivered in this way than to have the uterus emptied from below, and the advantage to the patient of being permanently protected against pregnancy, which is considered a serious menace to her life, is considerable. If the patient is suffering from an attack of decompensation at the time when abortion is decided on, every cffort should be made to rcstore compcnsation beforc the utcrus is emptied. If compensation can be restored, the obstetrician has a choice of several methods for emptying the uterus, but I believe that the abdominal route under general anesthesia is the preferable method, irrespective of the period of prognancy. If, however, it proves impossible to rcstore satisfactory compensation, there is no question in my mind but that delivery by abdominal hysterotomy, under local ancsthesia, preceded by morphinc and scopolamine is the most satisfactory method. Such patients are poor risks for any of the general anestheties and will occasionally die as the result of their use. Paravertebral anesthesia has in my hands proved a very exhausting method to such a patient, although it produces satisfactory ancsthesia, and I should hesitate to employ spinal anesthesia on a patient with a decompensated heart on account of the marked changes in blood pressure which accompany it, though this feeling may not be based on sufficient grounds.

The results which I have had in Cesarean section at term and earlier with local anesthesia, preceded by morphine-scopolamine, have convinced me that this is the most satisfactory method for use in patients whose cardiac condition contraindicates a general anesthetic, and the operation is as easily performed on a patient three or four months' pregnant as at term, being completed by sterilization. The patient is thus delivered and protected against the dangers of future preguancies al a single operation.

The employment of the morphine-scopolamine preliminary to operation under local anesthesia, has, in my experience, proved most satisfactory, the patient not infrequently having no recollection of the operation. In preparation for the operation the patient is given gr. 1/6 of morphine and 1/200 gr. of scopolamine two hours before the time set for operation, the scopolamine being repeated two or three times at thirty to forty minute intervals until the patient is asleep. The patient's eyes are covered and her ears plugged with cotton before she is brought to the operating room. No unnecessary noise is permitted in the operating room. The abdominal wall is injected with one half per cent novocain, it being only necessary to prepare the skin and fascia. Neither the parietal nor visceral peritoneum requires treatment. An interval of at least ten minutes should elapse between the injection of the novocain and the beginning of the operation. If sterilization is to be performed 
the uterine portion of the broad ligaments should be anesthetized before the tubes are excised from the uterine cornua. I have found that by strict attention to detail cardiac patients who are often excessively nervous and hard to control can be brought to operation in a perfectly quiescent state and commonly have no recollection of the operation.

If it is decided that the patient is a fair risk for pregnancy, the pregnancy should be allowed to go on under close supervision. All possible strain should be avoided; active exercise, especially hill climbing and going up the stairs, should be eliminated so far as possible. The general hygiene, fresh air, diet, etc. should be carefully regulated. The bowels should be regulated. The urine should be examined at weekly intervals so that any signs of passive congestion may be discovered early. The patient should be instructed to take a two-hour rest in her every day, and to supplement this by spending one day a weck in bed during the early part of pregnancy and two days a week during the last three months. The blood pressure should be carefully followed, and a rise in blood pressure should cause grave concern on account of the extra burden thrown on the heart, and may be sufficient to warrant an abortion. Digitalis or other cardiac stimulants are to bo used if any signs of failing compensation occur. Digitalis may he employed to advantage in all cases in the last months of pregnaney and the rest periods may be extended if desirable.

If patients are thus kept under close supervision, any signs of eardiac distress will be discovered early and can be met by increased precautions in the majority of instances. If, however, the cardiac symptoms do not subside promptly, and especially if they show any signs of increase, immediate termination of the pregnancy is called for to limit the cardiac damage. This rule should be an absolute one if the pregnancy is less than six months' duration, since the attempt to prolong the pregnancy for several months in the hope of obtaining a living child in a patient whose cardiac condition is slowing signs of failure under proper care is almost sure to result disastrously and is not justifiable. In patients six months' or more advanced in pregnancy in whom the cardiae symptoms, though definite, are not alarming, an attempt may be made to carry along the pregnancy to viability if a sufficiently high value is placed on the child by the mother, so that she is willing to run the risk of scrious invalidism for the sake of a living child. The patient must, in these cases, be practically confined to her bed throughout the remainder of the pregnancy, and cardiac stimulants should be used as indicated. Delivery should be accomplished by Cesarean section under general or local anesthesia as soon as the child is believed to be sufficiently developed to live, in order to minimize the cardiac damages as far as possible, local anesthesia being the choice, if the cardiac symptoms are at all marked, and sterilization to avoid future pregnancies is advisable. Interference is seldom indicated in such cases before the 36 th week, unless urgently demanded by the cardiac condition, since so much has already been sacrificed by the mother for the sake of the child that its chances should be guaranteed as far as possible. It must not be forgotten that if the mother suffers from severe decompensation the child frequently dies as a result. Therefore, if the cardiac symptoms appear threatening, it is seldom 
or never justifiable to attempt to prolong the pregnancy for a problematical advantage to the child.

As a general rule in these cases I believe that the abdominal route should be selected, irrespective of the time when interference is advised, and that the patient should be sterilized to prevent the possibility of future pregnancies. The choice as to whether the operation should be done under a general or a local anesthetic depends on the degree to which compensation can be restored before the operation is performed, but operation under local anesthesia may well be applied to all cardiac cases who have developed any signs of decompensation.

The strain on the heart increases in all as the end of pregnancy approaches, and if we can spare the heart two weeks or more of this increasing burclen the prognosis for the patient's future will be better than if she is allowed to go to full term. Moreover in any cardiac condition which has given rise to symptoms, even though compensation has been completely restored, this strain should be lessened so far as the interests of the child permit. In all cases in which a definite decompensation has developed during pregnancy it should be recognized that future pregnancies are absolutely contraindicated, and that the possibility of chronic invalidism in the near future is a definite one at the best, even in the absence of all avoidable strain. Should pregnancy oceur again in such cascs the dunger to life and health is greatly increased and prompt abortion is indicated. For this reason sterilization is advisable.

The pregnaney should be ended by the method which will throw the least possible strain on the heart, which is, in my opinion, Cesarean section, under general or local anesthesia, according to the condition of the heart when operation is considered advisable, and the preferences of the individual operator. I believe firmly that by this method of treatment the damage can be limited as far as is possible by any method, but any failure of compensation during pregnancy means that considerable harm has been done, even though compensation. may have been restored by treatment, and that the patient's future is doubtful at the best. The more serious the decompensation the worse the outlook for the patient, and the earlier will she become a cardiac invalid.

Such patients must be advised that pregnancy should be under no circumstances again attempted, and sterilization at the time of the present delivery should be strongly advised, since by this method only can the possibility of pregnancy be absolutely precluded. In the cases in whom abortion is indicated in case conception occurs at a later date no chances should be taken.

If the paticnt goos through the pregnaney without developing any signs of decompensation, the method of delivery is of great importance and will vary in the individual patients with the nature of the heart lesion, the number of the pregnancy, and the estimated difficulty of labor. In primiparæ with mitral stenosis, or with an aortic lesion, delivery should, in my opinion, be accomplished by Cesarean section, preferably about two weeks before the estimated date of labor so as to spare the heart the increasing strain of the last weeks of pregnancy. There is no doubt that in the majority of cases a carefully guarded labor ended by an operative pelvic delivery as soon as the cervix is fully dilated 
will give immediately satisfactory results, but the strain of labor on the damaged heart will to some extent deplete its reserve and the future prognosis will be improved if the strain of labor is avoided. In these cases there is no reason for sterilizing the patient unless she requests it, owing to the fact that if she is willing to pay a certain price for one or more other children her experience during this pregnancy warrants her in undertaking the risk. In multiparæ who have had no signs of decompensation during pregnancy or at any other time I believe that a short, first stage labor, delivery to be accomplished by forceps or version as soon as the cervix ceases to be an obstacle, will give nearly as good results, but the length of labor in primiparæ, especially if examination gives any reason to suppose that the labor will be at all a difficult one, will throw such strain on the heart as to render an abdominal delivery the wisest course and ultimately result in unnecessarily shortening the patient's life. It is not a question in my mind of the immediate result, but of conserving the cardiac reserve so as to lessen the possibility of the patient's becoming a cardiac invalid in the years to come.

In patients with mitral regurgitation which has never caused any symptoms, I believe that the only precaution necessary is to avoid the strain of the second stage of labor by prompt delivery as soon as the cervix is fully dilated.

The same principles should be followed in patients who are believed to have myocardial change, although no definite heart lesion can be demonstrated. The condition of the heart muscle is even more important than the question of a valvular lesion, and in patients who are suffering from symptoms suggestive of myocarditis, whether acute or chronic, all possible strain should be taken off the heart. This is best accomplished by abdominal delivery at a fixed date, thus avoiding the strain which labor imposes on the heart.

I recognize that this method of treating eardiac patients may be criticized; that it may be said with truth that statistics do not warrant the assumption that young women with cardiac lesions are in so precarions a condition as to warrant such radical methods of treatment. The results obtained in any lyingin hospital, as shown by the records, will apparently prove that the great majority of patients with definite cardiac lesions will pass through pregnancy and labor without serious symptoms, and that it is only in the occasional primipara or in the woman who has had repeated pregnancies, perhaps against advice, that immediately serious results occur. I believe, however, that this is a case in which the hospital records only tell a part of the story. It is recognized that some patients with cardiac lesions, previously apparently in good health, either die during pregnancy and labor, or are left as cardiac invalids as a result of the strain. In my opinion it is impossible to predict accurately which patients will do well and which will suffer severely as the result of pregnancy. Furthermore the follow-up system of our lying-in hospitals has not been sufficiently devcloped to tell us what the future of these patients may be. I have seen a sufficient number of patients who have passed through one or more pregnancies without serious disaster only to become permanently invalided within a few years, to be absolutely convinced that it is part of the duty of the obstetrician to safeguard his patient's future by every moans in his power. 
T feet therefore that the line of treatment, which I have attempted to outline in this paper will do more to safeguard the future health of a patient and at the same time allow her the joy of one or more children than any other method of treatment, though, of course, I will admit that the most conservative of all methods of treatment is to forbid pregnancy to every woman who has a cardiac lesion, and to advise abortion if pregnancy oceurs.

443 Beacon STREeT. 